\title{
Design of the Control System for the Constant Tension Lifting and Dropping of the Submersible
}

\author{
Jianjun Zhang \\ College of Information and Control Engineering, Weifang University, Weifang, China \\ wf_zjj@163.com
}

Keywords: Constant tension; Fuzzy PID; Vehicle; Wave compensation

\begin{abstract}
It is required that launch and recovery winch has the controlled function of constant tension in the process of vehicle launch and recovery. It can reduce the impact of vehicle when waves seesaw. Constant tension control system was established based on Fuzzy-PID. Simulation analysis of this system was done. Simulation result shows that the system has good dynamic and steady properties.
\end{abstract}

\section{Introduction}

Water and recovery of underwater submersible ROV is one of the key links that can accomplish the task, ROV is a very expensive instrument. When working, a crane is required to be placed under the specified position under the water. But when it falls, the strenuous wobble of the hull causes the cable to move up and down ROV like a rubber band. If there is no wave compensation system, it may eventually cause the cable break and the loss of ROV on the seabed. Similar accidents have occurred many times.

In order to improve the stability and safety of the submersible, it is very important to choose a suitable control system. The traditional PID controller has simple structure and strong robustness, but there is a contradiction between tracking setpoint and disturbance rejection ability, so that the system cannot get the best control effect [1]. Now the control algorithm instead of single PID to control the situation, the application of improved PID control, fuzzy control, optimal control, neural network control, adaptive control, robust control and control means, the tension control system towards the development of higher control precision[2-6]. In this paper, a fuzzy adaptive PID controller is designed, which makes the submersible with high dynamic performance and automatic adjustment during the process of collecting and releasing.

Wave compensation is actually a kind of speed compensation. That is, the amount of the main feedback is the speed, which compensates for the change of the load speed caused by the wave effect, and ensures the lifting of the load at a predetermined speed. At the same time, the displacement and acceleration are required as reference conditions to confirm the law of velocity change and the position in the spectrum.

\section{Active Wave Compensation Scheme}

Active wave compensation technology is a new hoisting technique, which is accompanied by the increasingly developed and frequent offshore operations. The wave compensation system has been widely used in foreign ships and offshore platforms, and has become an essential technology in the field of marine engineering. It occupies a very important position [7,8]. Compared with the mature situation of foreign wave compensation technology, the domestic research and application in this field are relatively backward.

Because MRU detects the speed of the hull of the ship at this time, and the wave compensation needs to be synchronized, that is, when MRU sends the detected ship heave speed signal to the winch, it is also necessary to send the acceleration signal of the wave heave and change, at the same time, At the same time, the system must constantly compare the compensation error at the first time, that is, the difference between the heave velocity detected by MRU and the actual speed of the drawworks. The three determine the wave heave velocity that the drawworks need to compensate. 
The basic process of system implementation is motion reference unit (MRU), force sensor and so on to detect ship displacement, fluctuation speed, cable pressure and tension, and transfer data to computer control system. According to the current ship error and the rate of error change, the computer control system gives the control signal after computation, and transfers it to the hydraulic drive system (hydraulic motor). According to the size of the control signal, the hydraulic system determines the size and direction of the valve's opening, so as to determine the speed and steering of the hydraulic motor. The hydraulic motor drives the mechanical execution system (winch) to complete the wave compensation function, at the same time, the detection system constantly feedback the measured load, the actual displacement of the ship, the tension of the rope and other parameters to the computer control system. According to the error and error rate of change, the computer control system calculates the size of the next cycle control signal and transfers it to the hydraulic system to control the next cycle.

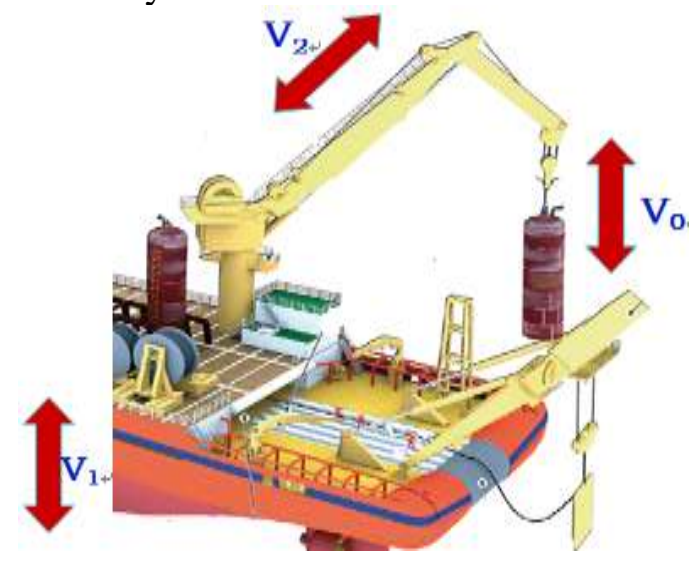

Figure 1. Velocity signal detection diagram in wave compensation process

The closed loop fuzzy PID control algorithm for the heave compensation is shown in Eq. 1.

$$
V_{1}+V_{2}-V_{0}=\delta \rightarrow 0
$$

In Eq. $1, \mathrm{~V}_{1}$ is the ship lift speed, $\mathrm{V}_{2}$ is the speed of the motor, $\mathrm{V}_{0}$ is the speed of the goods and $\boldsymbol{\delta}_{\text {is adjustment error. }}$

\section{Fuzzy Adaptive Tuning PID Control Principle}

The fuzzy controller uses the system error E and the error change EC as the input statement variable, so it has the function similar to the conventional PID controller. The system using this kind of fuzzy controller can obtain good dynamic characteristics, but the static performance cannot be satisfactory, and the static error cannot be eliminated. It is known from the linear control theory that the integral control can eliminate the steady state error, but the dynamic response is not very good. The dynamic response of the proportional control is fast, and the proportional integral control can not only obtain high steady state accuracy but also have high dynamic response. Therefore, the PID control strategy is introduced into the fuzzy controller to form the fuzzy PID control $[9,10]$, It is a way to improve the steady-state performance of the fuzzy controller. At present, this kind of composite controller has many forms, and its working principle is also different.

The core of the fuzzy PID control design is to sum up the technical knowledge and practical experience of the engineering designers, and to establish a suitable fuzzy rule table. The fuzzy control table with three parameters, ratio coefficient, integral coefficient and differential coefficient being adjusted respectively is obtained [11].

The schematic diagram of its control is shown in Fig. 2. 


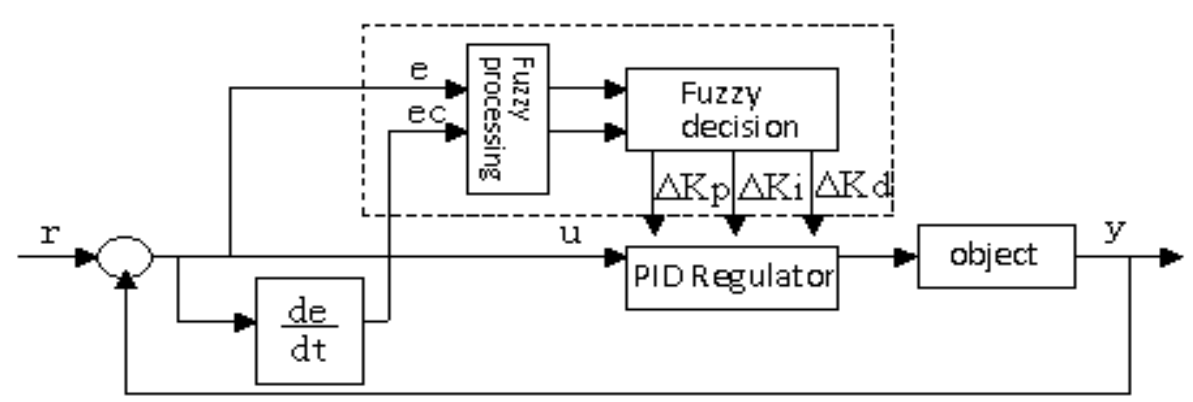

Figure 2. Schematic diagram of fuzzy adaptive PID control

Determine the Input and Output and its Membership Function. The input amount is e and the variation rate EC, the output is the variation of PID control parameters $\Delta K_{p}, \Delta K_{i}$ and $\Delta K_{d}$. The fuzzy sets of the input error quantity e, the error change amount ec and the output quantity $\Delta K_{y}, \Delta K_{\mathrm{i}}$ and $\Delta K_{d}$ are all $\{\mathrm{NB}, \mathrm{NM}, \mathrm{NS}, \mathrm{Z} 0, \mathrm{PS}, \mathrm{PM}, \mathrm{PB}\}$, their domains are $\{-6,-5,-4,-3,-2$, $-1,0,1,2,3,4,5,6\}$, therefore, a discrete set of 13 integer elements is formed. The input and output are all trigonometric membership functions, and their membership is zero at a given range.

Determine the Fuzzy Control Rule Table. The core of fuzzy controller design is to establish an appropriate fuzzy rule table based on expert knowledge and practical experience, and get the fuzzy control table of three parameters of $K_{y}, K_{i}$ and $K_{d}$. The fuzzy rule table of $\Delta K_{y}, \Delta K_{i}$ and $\Delta K_{d}$ is shown in Table 1.

Table 1 Fuzzy control rule table

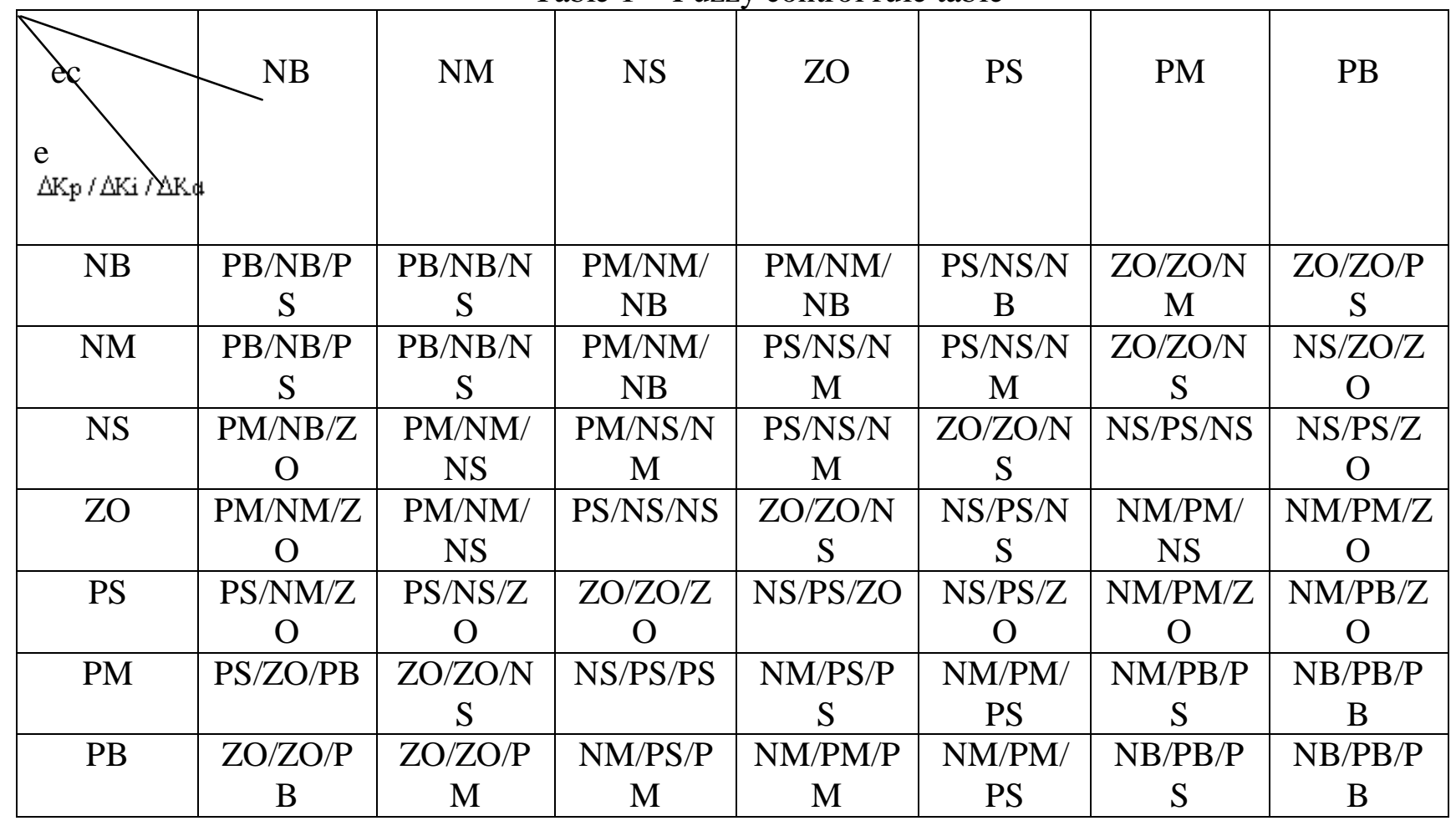

The fuzzy PID controller adjusts the calculation equation of PID parameters, as shown in Eq. 2.

$$
\begin{aligned}
& K_{P}=K_{P}^{\prime}+\Delta K_{P} \\
& K_{I}=K_{I}^{\prime}+\Delta K_{I} \\
& K_{D}=K_{D}^{\prime}+\Delta K_{D}
\end{aligned}
$$


In Eq. 2, $K_{P}^{\prime}, K_{I}^{\prime}$ and $K_{D}^{\prime}$ are the initial set of PID parameters, while $K_{P}, K_{I}$ and $K_{D}$ are the three outputs of fuzzy controller, and the three control parameters of PID can be automatically adjusted according to the state of the controlled object.

\section{Simulation}

Set up the simulation block diagram as shown in Fig. 3.

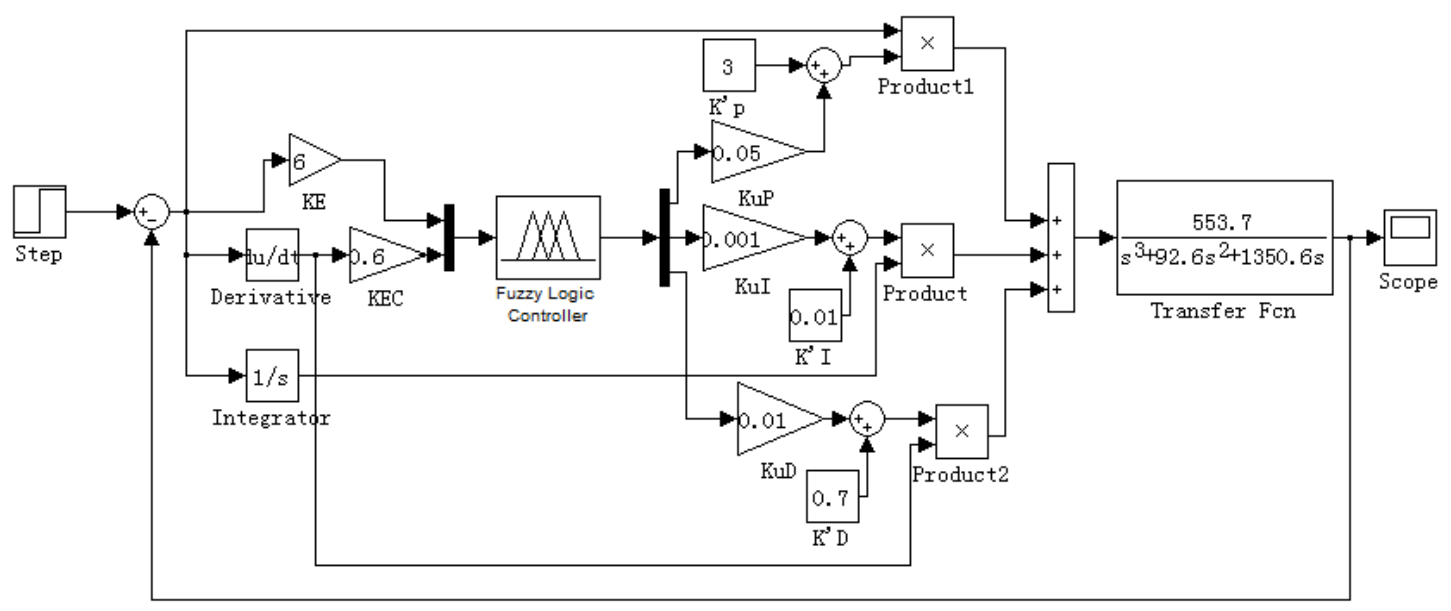

Figure 3. Fuzzy self tuning PID control simulation diagram

The simulation contrast curve of PID control and fuzzy self-tuning PID control can be obtained as shown in Fig. 4.

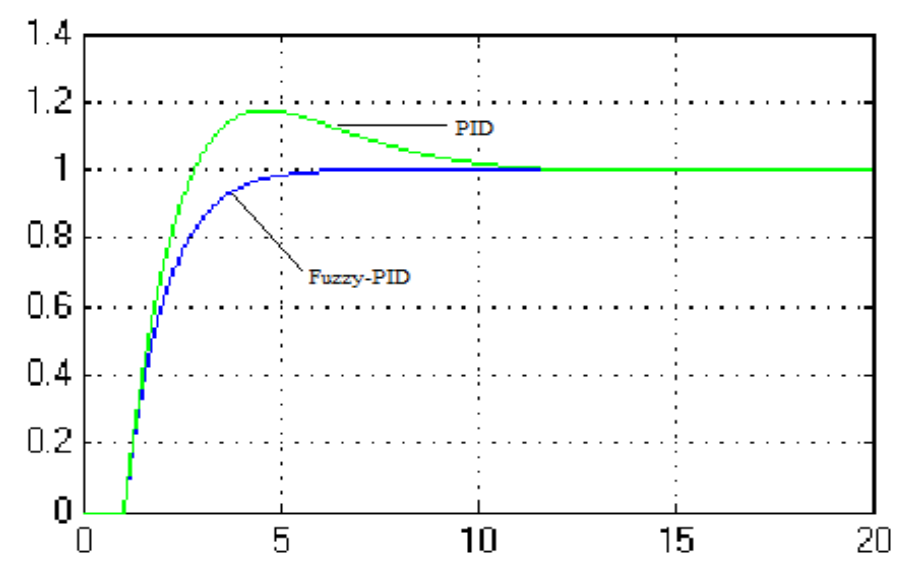

Figure 4. System simulation diagram

Through the simulation experiments of the two control methods about PID and fuzzy PID, different simulation curves of control effect are obtained. Comparison of the two can be seen in the response curve, such as: fuzzy PID control compared with PID control, with faster and more accurate response, smaller overshoot, oscillation and less adaptability, more robust, more suitable for the platform of complex condition control system control.

\section{References}

[1] S.Y. Yang and G.L. Xu: Industry Control and Applications, Vol.30 (2011) No.11, p.21-24. (In Chinese)

[2] D. Li: Research on Tension Control for Winding System (MS., Xi'an University of Science and Technology, China 2007), p.40-41.(In Chinese) 
[3] J.K. Liu: Advanced PID Control MATLAB Simulation (Fourth Edition)(Publishing House of Electronics Industry, China 2017), p.247. (In Chinese)

[4] J.H. Lee, Y.W. Yun, H.W. Hong and M.K. Park: International Journal of Precision Engineering and Manufacturing, Vol.17 (2016) No.2, p.157-162.

[5] H.X. Zhao, D.G. Chang: Applied Mechanics and Materials, Vols. 321-324 (2013), p. 1748-1752.

[6] G. Zhen, B. Li and Y.Z. Liang: Modern Electronics Technique, Vol. 40 (2017) No.21, p.131-135. (In Chinese)

[7] R.J. Huang: Research on the Electro-hydraulic Lifting Control System with Heave Compensation (MS., Shanghai Jiao Tong University, China 2014), p.2. (In Chinese)

[8] H.L. Yan, X. Miao, W. Wang and L. Cheng: Manufacturing Automation, Vol. 38 (2016) No.10, p.29-32.

[9] Y.S. Zhang, T. Yang, C. Li, S.S. Liu, C.C. Du, M. Li and H.L. Sun: Aerospace Science and Technology, Vol. 36 (2014), p.21-26.

[10]Z.C. Zhuang: Study on Control Algorithm of Agricultural UAV Stabilized Platform Based on Fuzzy PID Control Technology (MS., Zhejiang University, China 2016), p.34. (In Chinese)

[11]B.Z. Du, T.C. Lin and T.B. Zhao: International Journal of Computers Communications \& Control, Vol. 10 (2015) No.6, p.812-824. 